\section{Entrevista: José Paulo Netto}

Interview: José Paulo Netto
José Paulo Netto é Professor Emérito da Universidade Federal do Rio de Janeiro (vinculado à Escola de Serviço Social) e um conhecido intelectual marxista brasileiro. Doutor em Serviço Social, Netto se destaca como autor de obras que também apresentam, de forma didática e sem reducionismos, o pensamento marxista. Dentre tais obras, lembramos O que é marxismo (Brasiliense) e, mais recentemente, o livro Economia politica: uma introdução crítica, em co-autoria com Marcelo Braz (Cortez), e o volume, com a colaboração de Miguel Yoshida, de Marx-Engels, Cultura, arte e literatura: textos escolhidos (Expressão Popular). Com Carlos Nelson Coutinho, organizou três volumes de textos de G. Lukács (O jovem Marx, Socialismo e democratização e Arte e sociedade, todos pela Editora UFRJ).

Nesta entrevista, ${ }^{1}$ Netto discute principalmente a dialética a partir da matriz marxista, entendendo-a tanto como um método de apreensão da realidade quanto como o movimento do real. Para Netto, Marx, a despeito de ter deixado poucos escritos sobre o tema, constitui uma referência fundamental para aqueles que buscam, hoje, pensar e transformar de forma objetiva a realidade. Seguindo esta temática, a entrevista trata ainda da relação entre teoria e prática, das potencialidades do conhecimento científico e da lógica acadêmica contemporânea.
José Paulo Netto is Professor Emeritus at the Federal University of Rio de Janeiro (linked to the School of Social Service) and a known Brazilian Marxist intellectual. Holding a Doctorate in Social Work, Netto stands out as the author of works that have also outlined Marxist thought in a didactic manner and without any reductionism. Among these works, we mention "O que é marxismo" (Brasiliense), more recently "Economia política: uma introdução crítica," in co-authorship with Marcelo Braz (Cortez), and the volume, with the collaboration of Miguel Yoshida, from Marx-Engels, "Cultura, arte e literatura: textos escolhidos" (Expressão Popular). With Carlos Nelson Coutinho, he organized three volumes of texts written by G. Lukács ("O jovem Marx", "Socialismo e democratização" and "Arte e sociedade", all by Editora UFRJ).

In this interview, Netto discusses, mainly, dialectics under the Marxist framework, understanding it both as a method of apprehending reality and as the movement of the real. To Netto, although Marx did not write much on the subject, he is an essential benchmark for those who today are looking to analyze and transform reality objectively. In line with this theme, the interview also deals with the relationship between theory and practice, the potential of scientific knowledge, and the contemporary academic logic. 


\section{Revista}

Para o pensamento marxista, a dialética nomeia tanto um método de conhecimento da realidade quanto o movimento da própria realidade. Eu queria que você falasse um pouco sobre esse conceito. Você poderia discorrer sobre ele, em linhas gerais?

\section{José Paulo Netto}

Quando pensamos na palavra 'dialética', vemos como certas categorias filosóficas, quando se tornam de uso comum, entrando na linguagem cotidiana, na mídia etc., frequentemente perdem o seu sentido rigoroso. Eu costumo dizer, brincando, que a palavra 'dialética' é uma espécie de panaceia ou recurso de macumba que resolve todos os problemas. Quem tem uma fumaça de cultura de esquerda, quando se depara com alguma coisa complicada, geralmente afirma: "Isto é um processo dialético". Com isso, não se diz coisa nenhuma. Se tratarmos o tema com um mínimo de rigor e seriedade, para além do senso comum, veremos que a palavra comparece no marco das noções e conceitos ainda da nascente filosofia, na Grécia. Então, dialética denotava um método discursivo, uma forma retórica. Ao longo da história da filosofia no Ocidente, ora a dialética se referiu a esse significado original, ora ganhou outros sentidos.

Na entrada da Modernidade, ela se constituiu como pedra angular do pensamento de Hegel, um filósofo que é, até hoje, para muitos, um pensador enigmático ou, no limite, cheio de obscuridades. Para Hegel, o que era dialética? De forma muito breve, pode-se dizer que era um modo de pensar o mundo, um 'método'. Em Hegel, esse método constitui uma superação da grande tradição intelectual que vem desde Aristóteles. Se você fala em método, logo está pensando em lógica. Aristóteles é o fundador de uma lógica rigorosa que vai ser conhecida nos manuais de filosofia como 'lógica formal', que se funda numa série de princípios e elementos. Um princípio importante, por exemplo, é o da nãoidentidade: $A$ não é igual a não- $A$. Hegel diria que essa é uma forma de pensar o mundo que não é falsa, mas é unilateral, insuficiente. Por quê? Porque $A$, se é diferente de $n a \tilde{o}-A$, é simultaneamente igual a não- $A$. Pode parecer muito confuso, mas o que Hegel está querendo dizer é que o 'mundo é um processo, movimento'. Em Hegel, o ser é processualidade. A dialética, para ele, é o método para pensar o mundo enquanto movimento.

\section{Revista}

Como se situa a contradição no pensamento hegeliano?

\section{José Paulo Netto}

O movimento do ser não é um movimento qualquer: é na verdade um automovimento, ou seja, um movimento que tem a sua força motriz, a sua dinâmica, no próprio ser. E, além de não ser movimento qualquer, é um movimento que tem seu dinamismo fundado na contradição. $A$ é ao mesmo tempo $A$ e não- $A ; A$ é ao mesmo tempo a afirmação de si contendo forças que negam essa afirmação. É desse confronto entre a afirmação de $A$ e aquilo que é a negação de $A$ que vai surgir o diferente, o outro. Mas o outro, se é novo em relação a $A$, traz em si os traços da positividade de $A$. Por isso não é uma simples negação: é uma negação da negação que conduz a um novo - Hegel diria: em um nível superior - mas conservando, metamorfoseados, elementos originais. Isso seria a dimensão tríplice do movimento da lógica dialética de Hegel: uma afirmação, uma negação e a negação da negação, que se pode chamar de superação. Numa linguagem que se tornou comum: tese, antítese e síntese. Mas isso não significa que aquela lógica formal que vem de Aristóteles é falsa; ela é apenas unilateral, insuficiente. O método dialético supera essa unilateralidade.

Você dirá: isso é muito complicado, muito confuso, muito difícil! o difícil não é o método. Porque esse método apreende que aquilo que ele estuda - o ser, que está sempre em movimento, dinamizado pelas contradições - é que é complexo. Mas note: Hegel é um pensador idealista. Isso significa que, antes do ser material, tem-se um ser ideal, que cria, põe, esse ser material ao se contradizer, ao desdobrar-se, cindir-se, objetivar-se. Em Hegel, o primário é o Espírito que, num automovimento, instaura a sua negação, ela mesma também automovida. Uma série de pensadores operou uma análise crítica da obra de Hegel e, entre eles, muitos filósofos materialistas, que contribuíram para desenvolver a dialética numa direção diversa da de Hegel. Materialista, aqui, significa simplesmente o seguinte: no ser, o primado da existência (se você quiser: o primado ontológico) é material - não há nenhuma 
negação do espírito, das realidades anímicas, nada disso. Essas dimensões anímicas, do espírito, são produtos de uma longa, complexa e contraditória evolução do ser material. Para evitar qualquer equívoco, é melhor esclarecer: o materialismo a que aqui se refere implica o ateísmo, mas ele é muito mais do que o ateísmo.

\section{Revista}

Qual a relação histórica entre Marx e Hegel no que tange à dialética?

\section{José Paulo Netto}

Para ser curto e grosso: sem Hegel, Marx é impensável. Marx partiu da dialética de Hegel, recolhendo-a mediante uma crítica rigorosa e profunda; tomou-a como o movimento do real, ou seja, o automovimento efetivo da realidade, seja a natureza ou a história e a cultura (ainda que sua atenção básica tenha se voltado para a sociedade ou, na expressão de Lukács, para o ser social). Para Marx, pois, a dialética é objetiva. É importante destacar que o fato de só Hegel ter posto a dialética no centro da reflexão filosófica não significa que a dialética nasce com Hegel. Como algo objetivo, é claro que ela independe do conhecimento (ou da consciência) que se tenha dela. Ela é objetiva em razão de o ser constituirse dialeticamente. Mas foi com Hegel que ela se construiu como o que podemos chamar de 'dialética subjetiva', ou seja, como o modo mais adequado para compreender o ser e seu movimento - vale dizer, estritamente, como método. E o método de Marx é dialético exatamente neste sentido: como o modo mais adequado para conhecer o ser social.

É evidente que este é um método muito difícil de ser utilizado, porque os homens não pensam em abstrato: pensam a partir dos problemas, dos impasses, dos dilemas que são postos na vida cotidiana - com a sua heterogeneidade e a sua necessária imediaticidade. E nenhum homem pode suspender sua relação com a vida cotidiana senão por momentos. O cientista que está no laboratório, o filósofo que está refletindo, o romancista que está criando - nesses momentos, eles se suspendem de sua vida cotidiana e concentram e direcionam a sua energia para um objeto determinado. Nesses momentos, empenham toda a sua energia nas suas criações e descobertas. Mas eles depois tomam ônibus, enfrentam o trânsito em seus carros, voltam para casa, fazem suas refeições... A vida cotidiana, na sua imediaticidade, não mostra o movimento do ser.

\section{Revista}

O conhecimento dialético do mundo, então, é dificultado pela vida cotidiana, que mobiliza outros saberes, baseados, sobretudo, na experiência. Em que medida a experiência produz conhecimento?

\section{José Paulo Netto}

O conhecimento começa com a experiência, tem nela seu ponto de partida. Mas apenas o ponto de partida. Permita-me um exemplo bem simples. Você nasce aqui, no lugar $\mathrm{x}$, onde está sua casa, e tem a experiência cotidiana, ao longo de toda a sua vida, de ver que a sua casa está no mesmo lugar. Você observa e constata que o sol nasce num ponto específico pela manhã, naquilo que você chama de meio-dia ele está ali em cima e de tarde ele se esconde. O que a sua experiência cotidiana lhe mostra? Que a terra, onde está sua casa, está paradinha e o sol se movimenta em torno dela. Essa é a experiência imediata de todos os homens. Mas o que essa experiência mostra é verdadeiro? O conhecimento e a própria prática social demonstram que não. Sabemos, comprovadamente, que a terra não está parada, é ela que gira em torno do sol. Isso significa que o conhecimento rigoroso, profundo, da essência, da estrutura íntima dos fenômenos, não pode se limitar a essa experiência cotidiana. A aparência dos fenômenos é absolutamente importante porque começamos a conhecê-los a partir dela - o que não tem qualquer aparência não pode ser conhecido. Mas o conhecimento veraz, verdadeiro, parte da aparência dos fenômenos para encontrar a sua essência, a sua estrutura íntima e o seu movimento.

A nossa vida cotidiana e os seus quadros sociais contribuem para que o pensamento dialético seja pouco favorecido. Recorro a outra ilustração simples: imagine se você acorda e reflete: o mundo está numa mudança constante, cheio de contradições, tudo se move e tenho que conhecer o conjunto desta dinâmica para... Se pensar assim, você não se levanta da cama. É preciso manipular o mundo, intervir no mundo. E você precisa das oposições imediatas para poder se mover: precisa saber que o alto se opõe ao baixo, que o quente se opõe ao frio, que o sólido se opõe ao líquido ou ao gasoso etc. E essas discriminações 
que você faz não são falsas, são apenas unilaterais. Mas sem elas você não vive. Ora, o pensamento dialético implica que você, reconhecendo essas determinações - alto/baixo, perto/longe, branco/preto -, saiba que o branco é diferente do preto, mas que ele pode tornar-se preto e por assim adiante... Então, pensar dialeticamente traz uma série de exigências que vão na contracorrente da instrumentalização, da manipulação que nós praticamos com os fatos do mundo. Essa manipulação é necessária, mas nos dá uma visão que não é da totalidade do mundo, que não nos permite perceber a processualidade e a dinâmica do mundo e a natureza dessa dinâmica.

Pensar dialeticamente supõe uma formação teórica, pesquisa, estudo constante, e supõe que se aproprie da herança cultural que vem, pelo menos, de Hegel a nossos dias. Isso é absolutamente importante não apenas para termos uma relação mais eficiente com a natureza e com o mundo que instrumentalizamos e manipulamos, mas, sobretudo, para que possamos adquirir o conhecimento teórico-científico verdadeiro do conjunto da nossa vida. Porque a nossa vida não é um amontoado de pequenos segmentos: ela é uma totalidade que se insere numa totalidade maior, que é a nossa sociedade, que não existe sem a sua relação unitária (não identitária) com outra totalidade que é a natureza. São essas totalidades que constituem o ser. É evidente que isso supõe pesquisa, reflexão. É difícil compreender o mundo? É dificílimo. Porque o mundo é muito complexo. Nesse mundo, nesse pedaço de universo que nós estamos, não há nada de simples.

Conhecer o mundo, então, é muito mais do que sistematizar experiências cotidianas. A organização, a sistematização de experiências e sua discussão são extremamente importantes e úteis porque mostram, ademais, que qualquer processo de conhecimento eficaz tem que ser social e coletivo. Mas se não houver aí uma inserção e um insumo do ponto de vista teórico, nós podemos acabar concluindo que o sol gira em torno da terra... É preciso tomar muito cuidado com a ideia de que, a partir da prática, se constrói conhecimento. Não: a prática põe os problemas que o conhecimento teórico-científico pode esclarecer. Imagine um torneiro mecânico que, sabendo ler e escrever, reúna alguns companheiros de trabalho e desenvolva uma discussão coletiva para compreender a sua situação como trabalhador partir da sua vida prática, que se dá lá na fábrica. Se não dispuser de uma elaboração teórica que lhe abra caminhos para além da experiência prática e imediata, ele só vai conseguir chegar à ideia de que há injustiças sociais neste mundo: ele trabalha muito, a empresa cresce, seus proprietários individuais e coletivos enriquecem e ele não. Veja como o mundo é injusto! Isso não é falso, mas não leva à compreensão dos mecanismos que põem e repõem as bases da injustiça percebida. Para chegar a esta compreensão, ele precisa estudar a crítica da economia política, que não está na vida cotidiana: é resultado de uma larga elaboração teórica que partiu da vida cotidiana, mas produziu e utilizou categorias, investigações, instrumentos heurísticos para entender por que a realidade parece e é, de fato, segundo determinados padrões éticos - injusta. Se permanecer no nível imediato da sua prática, jamais ele vai encontrar uma jovem senhora - que hoje já é uma velha caquética - chamada mais-valia. Ninguém nunca cumprimentou a senhora mais-valia. Eu estou sinalizando isso porque importantes grupos e movimentos sociais se esforçam para elaborar um conhecimento sobre o mundo limitando-se à experiência cotidiana. Ora, este conhecimento tem que transcender a cotidianidade e sua prática imediata. É só nesta transcendência que a dialética do real pode aparecer. A dialética é um movimento real. Mas para que ela apareça como um movimento real, há que estar equipado intelectualmente para poder apreender esse movimento do real - ele não é imediatamente visível.

\section{Revista}

Voltando à vida cotidiana: para manipular o mundo, precisamos 'conhecê-lo' de alguma forma. Existem outros tipos de conhecimento além do científico?

\section{José Paulo Netto}

Sim, sem dúvida existem vários tipos de conhecimento. Tome outro exemplo simples. Você sabe perfeitamente que, para iluminar esta sala, precisa apertar o interruptor. Essa é uma forma de conhecimento. Mas você não sabe o que acontece entre apertar aquele comutador ali na parede e o acendimento dessa lâmpada incandescente: disso entendem o eletricista e, rigorosamente, o físico... Boa parte do nosso conhecimento do mundo opera assim. Você sabe ligar seu carro, 
sabe que tem que abastecê-lo, lubrificá-lo etc., mas não tem a menor ideia de como o motor funciona $-\mathrm{e}$, para dirigir bem, não precisa dominar o conhecimento de como ele funciona. Eu diria que esse conhecimento é prático-mental. Se você observar bem, verá que quase tudo o que você faz durante o dia é com esse tipo de conhecimento.

Existe outra forma, mais elevada, de conhecimento - a arte, por exemplo. Quando lê Machado de Assis, você tem uma clara ideia de como vivia uma parte da sociedade no Segundo Reinado, aqui no Rio de Janeiro. Mas eu posso também conhecer como vivia essa população recorrendo aos historiadores que trataram daquele período. O objeto destes últimos e de Machado de Assis, neste caso, é o mesmo, mas o modo do conhecimento é diferente. Um é arte, o outro é ciência. Se a ciência é indispensável para o conhecimento do mundo, isto não significa dizer que as outras modalidades de conhecimento sejam dispensáveis: não se pode conceber o mundo, quando a sociabilidade está desenvolvida, sem a arte e sem a manipulação prático-mental. Mas é a ciência que permite saber como o mundo é independentemente da sua subjetividade. É diferente do conhecimento que a arte oferece. Quando você conhece parte da sociedade do Segundo Reinado no Rio de Janeiro lendo Machado de Assis, o conhecimento oferecido pelo Bruxo do Cosme Velho tem como centro organizador a subjetividade humana. $\mathrm{Na}$ arte, o sujeito humano se compromete com o objeto: o objeto é apreendido numa perspectiva que eu diria, seguindo Lukács, que é 'para nós', para os sujeitos humanos. A perspectiva do cientista é outra; o biólogo, por exemplo, não estuda a célula 'para nós': ele quer saber o que a célula é 'em si', tal como ela é.

\section{Revista}

Como método, a dialética é o reflexo do real?

\section{José Paulo Netto}

Como método, a dialética não produz a realidade. O objeto é - perdoe-me a aparente tautologia - objetivo e efetivo, está fora da consciência dos homens. O que a dialética me permite é apreender o que se passa nele. Enquanto o que designei como 'dialética subjetiva', ela tem caráter de reflexo - é o mundo refletido no cérebro humano -, mas é fundamental sublinhar que esse reflexo não é um espelhamento. Ele implica que a mente, o cérebro, as faculdades intelectivas dos homens se mobilizem ativamente. $\mathrm{O}$ mundo é sempre um mistério a ser decifrado. Então, o reflexo do mundo não é o reflexo da aparência do mundo, da fenomenalidade - do ponto de vista da dialética, é o reflexo do movimento real do mundo.

\section{Revista}

Carlos Nelson Coutinho, no livro O estruturalismo e a miséria da razão, aponta problemas nas concepções que pensam separadamente o materialismo histórico ou o materialismo dialético. A dialética precisa ser histórica?

\section{José Paulo Netto}

Carlos Nelson tem inteira razão. A dialética é a expressão da história. A dialética é um processo objetivo, o movimento tanto do ser natural quanto do ser social. Mas a dialética da natureza não é igual à dialética da sociedade porque o ser social, embora surgido da natureza e a ela necessariamente vinculado, tem especificidades. Há movimento, há contradição, há avanço, há superação, tanto na natureza quanto na sociedade. Mas a dialética da natureza não pode ser equalizada à da sociedade. Por exemplo, a categoria de liberdade - categoria que é um traço pertinente da realidade social, um modo de ser do real social - não existe na natureza. Na natureza não há liberdade, há acaso, azar, acidente, mas não liberdade. Esta é uma característica específica do ser social.

Há outra categoria que não existe na natureza: teleologia, a ação dirigida segundo fins, o movimento que tende a uma finalidade que é pressuposta no seu início. Eu posso perguntar por que uma macieira dá maçãs e não peras, mas eu não posso perguntar para que ela dá maçãs - na natureza, há causas, mas não há motivos, intencionalidades. Com isso, quero dizer que na natureza há movimento dialético, mas a dialética social não é a natural. Há uma história da natureza, como há uma história da sociedade. E, na medida em que a sociedade se constitui, ela interfere na natureza. Mas a história da natureza guarda uma diferença fundamental: não somos nós, os seres sociais, que a fazemos. Nós fazemos a nossa história, mas não fazemos a história da natureza. Nós também não fazemos a nossa história com liberdade absoluta, porque isso não 
existe (liberdade é escolher entre alternativas concretas). A determinação dessa diferença (fazemos a nossa história, mas não fazemos a história da natureza) coube a um pensador que precede Hegel, Vico, que, sem saber, já estava fazendo dialética. Essa é a diferença essencial entre a história da natureza e a história social. Nos processos da natureza, não há sujeitos - exceto o ou os deuses, mas esta é uma questão de religião e não de ciência. A sociedade tem sujeitos sociais, coletivos, grupos, classes. Na natureza, onde não existe liberdade, mas acaso, predominam causalidades e necessidades. Na sociedade, há leis causais, necessidades, mas há também alternativas: se a sociedade não tem um fim predeterminado, os homens, que atuam sempre coletivamente, têm projetos, finalidades e objetivos. Isto mostra que há história no ser natural e no ser social, mas que esta história tem especificidades em cada um desses níveis, que são distintos, porém unitários. A sociedade e a natureza fazem uma unidade, mas unidade não é junção de iguais, não é identidade, é unidade entre diferentes. O ser é a unidade - não a identidade - entre o ser natural e o ser social. Isso é dialética. Dialética é história, do ponto de vista do seu processo real.

\section{Revista}

O conceito de dialética pressupõe uma verdade objetiva. No caminho contrário, pensadores pósmodernos têm defendido, entre outras questões, a impossibilidade de se conhecer objetivamente o mundo. A constatação, dialética, de que o real é contraditório não pode reforçar essa impossibilidade?

\section{José Paulo Netto}

Eu diria que a ideia de que o mundo e o ser são movimento é uma conquista da Modernidade. Já na Antiguidade, vários pensadores tiveram essa percepção, mas foi na Modernidade, resultado do desenvolvimento da Ilustração, que as ideias de movimento e processualidade se instauraram no pensamento ocidental. Do ponto de vista dialético, a natureza desse movimento é que ele é um automovimento: não é preciso que alguém lhe dê um empurrão. O ser tem contradições internas, imanentes, que produzem o seu movimento. Desde o século XIX, não há um pensador sério que negue a dinâmica da realidade, seu movimento - alguns até negam do ponto de vista da realidade natural, já que há, neste campo, tendências muito fortes contra a noção de evolução da natureza. Mas não há nenhum pensador sério que negue o movimento da sociedade. O problema está em conceber qual a natureza desse movimento, em primeiro lugar. Em segundo lugar, qual a concepção desse movimento na relação sociedade-natureza. Eu diria que nenhum dos pensadores pós-modernos nega o movimento. Boa parte deles até invoca a dialética para fundar a sua noção de movimento. $\mathrm{O}$ problema é que a esmagadora maioria dos pensadores sociais pós-modernos - aqui, é preciso enfatizar o trato da sociedade, uma vez que qualquer ideia de 'ciência dura' pós-moderna já foi suficientemente ridicularizada (lembre-se de Sokal) - trabalha uma noção de movimento ao mesmo tempo em que retira de cena categorias sem as quais essa noção não faz nenhum sentido. Por exemplo, a categoria de totalidade. O pensamento pós-moderno, numa operação epistemologicamente ilegítima e histórica e socialmente artificiosa, além de pouco séria, suprimiu a categoria de totalidade, que é por ele identificada ao 'totalitarismo'. Isso é um absurdo: totalidade é uma categoria ontológica e teórico-metodológica; 'totalitarismo' não é nem categoria, é uma das pérolas do cretinismo sociológico ou da teoria política liberal. Neste sentido, o que muitos pós-modernos entendem como movimento não tem nada a ver com a concepção de movimento dialético, seja como ele aparece em Hegel, seja como ele aparece concretizado historicamente sobre fundamentos materialistas em Marx.

\section{Revista}

Uma das críticas pós-modernas ao conceito de dialética é que ele supõe um movimento ordenado do mundo, que eliminaria a ideia de liberdade e de acaso..

\section{José Paulo Netto}

O pensamento dialético que vem de Hegel pode ter operado inicialmente como um elemento de hipótese, como diríamos hoje, mas é algo que a investigação de Marx comprovou, estudando, por exemplo, o movimento do capital.

O movimento que expressa o modo de ser do ser da sociedade não é aleatório, nem arbitrário ou irracional: dispõe de uma racionalidade. A realidade social não é uma totalidade amorfa nem inarticulada: ela tem forma, é estruturada, con- 
creta, dinâmica e dispõe de racionalidade. Não é arbitrária nem aleatória, o que não significa que não haja acasos, mas isso é o excepcional. A totalidade social não é fechada, está em movimento, pode negar-se. O fato de ser uma totalidade aberta não faz com que ela deixe de ser uma totalidade. Uma totalidade fechada não conheceria mudanças: o movimento seria, no limite, circular. A realidade social é uma totalidade que se movimenta no sentido de sua desestruturação para gerar uma nova estrutura. Nesse sentido, há relações causais necessárias nessa totalidade. E isso não é nenhum determinismo.

Tomemos o exemplo da economia política: se é próprio do movimento do capital a tendência à concentração e à centralização, um dos resultados necessários é o monopólio. Não se trata de nenhum determinismo prévio, mas da implicação incoercível daquelas tendências. Eis aí um exemplo da racionalidade dessa totalidade, que não é uma racionalidade posta de fora. Onde entra a liberdade? Depende do que entendemos por liberdade. Para Hegel, a liberdade é a consciência da necessidade. Se conhece a necessidade, você é livre, mesmo que não cancele a necessidade. Essa caracterização é importante, mas me parece incompleta, porque não deixa claro onde entra o agir humano. Eu prefiro trabalhar, na tradição dialética que vem de Marx e é expressa por Lukács, com a ideia de que a liberdade é a possibilidade de escolher entre alternativas concretas. Se não há alternativas, não há liberdade. Portanto, a liberdade não é um componente de tipo subjetivo, tal como se expressa em formulações como "Estou preso, mas como sei que estou preso, estou livre". A liberdade é concreta. $\mathrm{O}$ fato de reconhecer a necessidade de que concentração somada à centralização leve ao monopólio não me torna livre; porém, se eu sei que concentração e centralização são movimentos objetivos do capital, que, portanto, não estão na minha cabeça; se sei que o capital não é uma coisa, e sim relação social, entendo que eu estou incluído nisso, que posso escolher outro caminho. Posso escolher, por exemplo, suprimir as bases da concentração: a propriedade privada dos meios de produção. Essa é uma alternativa que eu posso escolher concretamente: há uma via capitalista e uma via socialista. Mas, veja: eu não suprimi a necessidade. É arquiconhecido o mito de Ícaro, aquele que queria voar. Mas o avião só voa porque é mais pesado do que o ar. De balão, você não voa, flutua. Você suprimiu a lei universal da gravitação dos corpos? Não. Você consegue voar exatamente porque a conhece. Nós não suprimimos a necessidade: conhecendo a necessidade, nós podemos utilizá-la.

\section{Revista}

Dialética como método é compatível com as metodologias específicas da ciência contemporânea?

\section{José Paulo Netto}

Os parâmetros da produção científica e a organização da produção científica institucional contemporâneas têm bases claramente neopositivistas (no livro do Carlos Nelson que você mencionou, há excelentes observações sobre o neopositivismo). E isso é uma camisa de força. A organização institucional da produção do conhecimento expressa o fato de que ela está subsumida a uma lógica macroscópica maior, que é a lógica do capitalismo contemporâneo. No interior dessa organização institucional, nunca se pesquisou tanto, nunca se produziu tanto e... nunca se conheceu tão pouco sobre o conjunto da sociedade. Eu penso que a mesma coisa vale - mas aí sou muito cauteloso - para o domínio das 'ciências duras'. Penso que aquela que tem avançado mais é a biologia contemporânea, até porque, nela, o processo dialético do ser se impõe obrigatoriamente. Penso, inclusive, que os avanços que virão da engenharia genética, do longo processo - por exemplo - de análise do genoma, vão colocar a dialética no centro da biologia. A biologia hoje restaura a dialética: ela tem que pensar movimento, contradição e transformação. Na física, isso em parte já ocorreu, mas muito subordinado ao complexo industrialmilitar.

Em qualquer caso, seja nas ciências sociais, seja nas 'ciências duras', a questão da organização institucional da produção científica deve indagar quem financia e o que se financia. Veja como mudou e vai mudar mais ainda a produção na área das ciências sociais desde que, entre nós, o financiamento institucional passou a se organizar mediante os chamados editais. Quando você concorre a um edital, ali já está demarcado por onde vai a pesquisa. É claro que, nestas condições, a tão invocada liberdade de pesquisa torna-se pura retórica. Dificilmente se pode conceber esta liberdade quando o marco da pesquisa está determinado pelo financiamento. Em geral, 
este marco expressa claramente uma concepção de conhecimento voltado para a manipulação do real. Para manipular o real, eu não preciso conhecer a sua essência. Esse é o caráter neopositivista - não é o positivismo do velho [Auguste] Comte. Não. É o neopositivismo como forma de pensar a realidade a partir da sua manipulação. Penso que isso é terrivelmente nefasto para a dialética. Para o pensamento dialético, no processo de conhecimento, o elemento que dirige o processo, que implica a sua direção, é o objeto, não o sujeito. Assim, não se pode escolher o método arbitrária ou aleatoriamente. Isso, do ponto de vista dialético, é um absurdo. Há que se ter como método aquele que seja capaz de apreender o movimento do objeto. Na academia, frequentemente se identifica método com um conjunto de regras formais e intelectivas para o trato do objeto. É evidente que essas regras são fundamentais: não casualmente, foi Durkheim quem deu o passo decisivo neste sentido. Mas isso não é método, é técnica de pesquisa. Por essas e outras, penso que hoje, na universidade, fazer pesquisa fundada no método dialético significa cada vez mais remar contra a corrente.

\section{Revista}

Se o método é histórico, a dialética tem uma relação direta com esse 'objeto' que é a sociedade capitalista? A síntese final é a revolução?

\section{José Paulo Netto}

Vamos ver se eu consigo responder à sua pergunta de maneira a evitar qualquer finalismo ou teleologismo. Uma das críticas ao marxismo é que ele seria determinista ao afirmar que a 'revolução', ou 'o socialismo', é 'inevitável'... Ora, no Manifesto Comunista, o mais 'clássico' dos textos de combate de Marx e Engels, lê-se que as lutas de classes resultam sempre na vitória da classe que traz nas suas mãos o futuro - no caso da sociedade que Marx e Engels têm em vista, o proletariado - ou na destruição das classes em presença. Portanto, as lutas de classes em nossa sociedade podem não resultar em socialismo, podem não conduzir ao comunismo. Podem derivar na barbárie: a destruição das classes em presença. E é precisamente por isso que é necessária a iniciativa política: é esta que pode direcionar os processos de lutas para um fim. Não há finalismo imanente na história: a teleologia é posta pela ação organizada dos homens (que, enfim, constituem, em suas relações, as classes). Uma coisa me parece clara: as contradições da ordem burguesa, exponenciadas nos últimos 30 anos, terão o seu desfecho. Uma possibilidade é o processo revolucionário capaz de suprimir a ordem burguesa. Outra é, simplesmente, a destruição da vida sobre o planeta. A alternativa concreta é, pois, socialismo ou barbárie.

\section{Nota}

1 Entrevista concedida a Cátia Corrêa Guimarães, coordenadora de Comunicação, Divulgação e Eventos da Escola Politécnica de Saúde Joaquim Venâncio, da Fundação Oswaldo Cruz. 